\title{
Urbanism, Architecture and Modern Urban Development
}

\author{
Hossein Hakimi $^{1}$, Sajjad Yari Firoozabadi ${ }^{2}$
}

\begin{abstract}
Developing countries are subject to quick cultural changes as they evolve. Modern cities have been constructed by the interactions between different types of subjects. The identities of the actors that have been altered by communication in different forms of systems need new structures and infrastructures. The infrastructures should be in alignment with this evolving situation. The substructure is one of the objective reasons for the communication of citizens as, in this regard, individuals (citizens) will experience more emotional enjoyment from the freedom based on the number of facilities available to them. As with both objective and subjective discourses, the city will become more prominent in the modernized architectural structures if it is within the subjective scope of the citizens' free choices. To survive in this vibrant era, architecture has no choice but to be combined with the technologies derived from the modern science. Therefore, if technology or architecture is one of the options available to the citizens of metropolitan cities, it will create small communities and places due to its discursive nature and its locality and amusing quality where the citizen and city are placed in a dynamic situation as an actor and substructure. Our approach in this article has been scientific research and the impact of technology-architecture on modern urban development is studied based on the views of George Simmel and the city's dependence on the architecture which has derived from this notion.
\end{abstract}

Keywords: Interaction, architecture, city and modern urban development, citizenship, infrastructure, technology

\section{Introduction}

The city that includes a set of masses and the community leads Man at a very broad level and in the context of complex communications towards the achievement of perfection. On the other hand, the city is not only a place for habitation and residence, but also an "oasis" that crystallizes the soul of the community and extracts an identity from it. Therefore, the city has an identity that depends on the culture of its inhabitants. Simmel considers the modern metropolis to be the locus of the pressures and the focus of modernity established by the monetary economy which expands momentarily. The metropolis is a base for the circulation of people, groups, goods and the forms of interaction as well as their representations. Understanding the concept of modern metropolis from the perspective of circulation domination (in contrast to the production and consumption of goods, image, and capital) involves the focus on the forms of movement and motion that take their own nature from advanced technologies and virtual spaces. This in turn means being away from the continuity and immediacy of experience, or in the words of Giorgio Agamben, "the destruction of experience" and the approach towards separation, mediation, and abstraction. Each fragment in the metropolis has some manifestations that require a comprehensive study of the 
perspective of the humanities. In this study, the gap or connectivity that has occurred in metropolises in the era of the virtually absolute domination of virtualism will be addressed in cultural spheres and specifically in architecture. Given that the nature of the city is a realistic representation of theatrical-human movements, it can become the location or neighborhood for the citizen (the addressee) where the architecture and "infrastructure" are crucial variables and components for their appearance. The effects of location and architecture on the human fragmentation or gathering in the real sphere and the interrelationship of these components with metropolis will be examined as well.

\section{Practical Concepts}

In its current state, every city has gone through a process and should also move forward with its internal developments and productions. According to Lewis Virsha, the city is "a large and dense phenomenon with a permanent and social habitat which is heterogeneous in demographic terms.” From Max Weber's perspective: "It is a closed and dense habitat". Robert Ezra Park says: "The city is the result of competition in the natural environment." Moreover, in more recent theories, the cities are the growth machines (growth, development and change) and these growths and changes create cities with different characteristics known as "techno-polis or metropolis". The identity of the new cities has undergone radical changes due to the authority of the discourse of virtual place and, in their essence, these changes involve some necessities when all the elements of a city must be in line with this modern sense of dynamism, especially in the field of "infrastructure". In his essay titled "The Metropolis and the Spiritual Life", Simmel writes that "a metropolis is the place where the contemporary culture is revealed in its original and most complete form. The metropolises focus on the ways in which social differentiation is influenced by the separation of all aspects of everyday social relationships" (Metropolis and the Spiritual Life - 1993). With an idealistic glance, the cities are the outcome of the era of industry and technology, all the elements of which depend on the definitions of actions and interactions. In different ways, the architecture and structures (i.e. infrastructure) which are the main pillars of the city's body and texture have moved beyond this level and has transferred the city from the virtual and simulated world based on real data (i.e. the size and plan based on reality) and has turned it into a real and objective subject. This means that "we walk in today's city in two worlds (or realities): the reality and the simulated reality that is a simulation-driven structure and does not have the dynamism of the virtual domain." Architecture can include a measurable space that is solidified and established or a set of relationships that are in a tangible space between humans in an orderly manner. Thus, the architecture includes a set of requirements and views the user as a mechanical object such as general (for example, a mosque) and partial functions (for example: the entrance, the hallway, the courtyard, the washing-room, the nave). The structural combination branch consists of a set of elements and building blocks that guarantee the stability and resistance of the building against any transformative or destructive static phenomena. The conceptual combination branch includes all the features of a form that in each case identify the concepts that determine social identity such as the proportions, geometry, decor, balance, contour, contradiction, symmetry, rhythm, filled and empty spaces, and open, 
half-opened and closed spaces. The physical combination branch encompasses all physical or bodily entities that can be measured and the environmental combination branch includes all the two-way and dynamic relations existing between the building and environment. Meanwhile, the sum of the established relationships between "culture" and "social interactions" is also part of this confrontation. The infrastructure (both in the context of the concept and structure) is one of the objective reasons for social and citizenship communication. This proposition also plays the role of the hypothesis and has a referable function in other cases. The neighborhoods are set as an objective phenomenon within a subjective discourse in the cultural "infrastructure" of the modernized metropolis. They can be a place for social gatherings from the realm of objectivity and the conscious human being (that is, the active agent) or rather the citizen is at the center of all collective and artificial human gatherings.

\section{City (Polis) [City, Architecture, Space]}

The Polis manifested its rational aspect in the glorious history of the golden age in ancient Greece with its rules and social classifications and, more importantly, by giving freedom to the slaves. "From the eighth century BC, Greece was organized into a state called Polis. The urban community and its religious ceremonies and the dominant ideologies of that era held festivals to revere and glorify the gods that enjoyed great popularity among the people, including the Dionysus for glorifying the god of wine, fertility and dance. This was a product from the Eleutherae village at the border between Attica and a region of Boeotia as a part of Athens with a long-standing feud with Thebes. This was turned into a habit that slowly gained some popularity in the city. These celebrations were held in several seasons for good harvests during the season of the dead and the rainy months of the year for a few weeks" (Easterling-8). The conceptobject called the city (Polis) produced a subject called the form-space that was institutionalized and manifested within the shortest period of time after its structural emergence in Athens. There were an inseparable pair and two domains of formation and representation. The most obvious dividing lines of these two phenomena which are the product of human geographic coexistence are the conscious man (the active agent) and the city and the space as an environment that takes shape by the interaction of actions, occurrences and relationships. These examples are somewhat complex and cannot be depicted. Perhaps, this is why the city is an environment perceived as a metaphor that occupies the human environment with many phenomena that we call "reality". We cannot understand all of these phenomena simultaneously and human beings only understand part of them. These perceptible phenomena, which are independent of us, are "objectivity." Space is part of the reality of the environment which is in the category of objectivity and has a form and function as with other phenomena in the category of objectivity. Not only it exists as an object independent of humanity and interacts with human beings, but it also has subjectivity in the form of a mental image. One's perception of the social and personal environment is a fundamental aspect of one's use of space. In fact, space is considered as an aspect of human existence in interaction with the different dimensions of "being-in-the-world" and life in plain words". Schultz quotes Heidegger and states: "You cannot separate man and space from each other. Space is 
neither an apparent object nor an innate internal perception. In this view, we can no longer consider space as an absolute or the absolute mind; rather, like any other phenomenon, it should be considered to have some hierarchies. Such an impression of space in the face of man constitutes it both as an objectivity being independent of Man that is perceived by him and a mental unit belonging to Man which is associated with that objectivity and highlights the concept of "place".

While modernists regard space as a phenomenon in line with the social purposes and, consequently, a function of social project structure, the postmodern scholars regard space as an independent and self-evident phenomenon that must be necessarily shaped according to the goals and principles of aesthetics. It does not even convey any universal and social goal other than the achievement of the endless and "neutral" beauty as a goal in itself.

\section{The unstoppable social-urban modernization and the status of the concept of "experience"}

In an essay titled "The Nature of Language", Heidegger writes: "Experience as something that is either physical, human or divine, means that something happens to us, and inflicts on us, dominates us, and makes us immersed in it and makes us change" (Agamben, 2012, 28). Therefore, experience is not ours; rather, it has an ontological precedence over our existence and decision. This means our experiential decision and practice do not create experience. Nevertheless, according to Agamben, the experience gained from the continuous individual-urbanism and modernization is something present, uninterrupted, direct, and personal. In the culture of our times, people are more distant and continue to give it a lower credit. There is no sign of the "first-hand experience" that formed the core of the social and intellectual life of the past generations when people achieved it by coming together. Like Benjamin, Agamben considers the main property of the contemporary times to be the devastation or the loss of the possibility of experience. He states: "The vulgarity and simplicity of everyday life is such that events can no longer be experienced in their own essence, but they can only be "passed down" or one can be unknowingly touched by them (Ibid., 2012, 55-56). He also believes that "the possibility of experience and the possibility of narrating experiences (and, consequently, the possibility of writing a personal autobiography) has been taken from the modern Man" (Ibid., 2012, 67).

However, in Simmel's terms, this personal and citizenship experience occurs in four forms in the social context at the heart of architectural structures and in the process of modernization or the new society: 1. The formal transition of the legal responsibilities from the groups to personal and individual responsibilities 2. The transition from the small-scale organizations combined with the homogeneity of activities between members to larger institutions at macro level combined with heterogeneity between members. 3 . The move from shared beliefs, even at the lowest levels associated with sharing mental activities and allowing individual intellectual achievements to be made possible. 4. Transition from compulsory social groups based on location and birth towards the formation of social groups where volunteers share common interests, such as labor organizations, feminist groups, and others cliques which are organized more individually 
and internally and also have a group solidarity" (Metropolis and the Mental Life - 1992). Simmel considers the modern experience as a discrete and transitory time in which the moment of escape and the perception of presence come together. He also considers the place (metropolis) as the dialectics of distance and proximity and considers causation as probability, occurrence, and accident (Ritz-2005-763). This central dimension of Simmel's analysis is about the culture of modernity in which the tendency for a growing social distinction is accompanied by a wide gap between the culture of action and the subject-centered culture. The main cores associated with this analysis are the metropolis and the advanced monetary economy.

"In the domain of the experience of modernity and in the sphere of circulation, exchange and consumption, one must focus on areas where the category of class, gender and ethnicity are often neglected. This is most obvious in the field of the circulation, where the things circulating are not related or connected to the people whose circumstances and conditions are involved in the process of circulation and exchange" (Freibersi, 2005, 27-28).

\section{Liberty as a modernistic-metropolitan component [architecture, urban development]}

Simmell: "Liberty is a problem that emanates from the expansion of social solidarity (freedom is a social and functional rather than individual or subjective state). All cities produce forces that both threaten and encourage the individual's new aspirations. This means that cities support individuality by supporting an extreme degree of specialization, while the division of labor threatens individualism" (The Philosophy of Money, 2004. 165). In response to the exploitative success brought about by the specialized division of labor for the citizens, new urban living conditions have given rise to a new range of individuality that stands in opposition to the massive depersonalization or even personalized cultural means. Furthermore, they sometimes consider themselves as the lords of the media or even the source of the production of new customs and signs (showmen, politicians, the proponents of any disturbance in any custom or laws such as human stability, etc.). What is even more dangerous (in my opinion) is social individuality which is represented in the form of signs of personal traits and strange characters (chaotic or anarchist or even in a permanent unconscious opposition). This is why there is antagonism between the two in the ideal of individualism. There is a correlation between the "self-determination" of the eighteenth-century libertarian uprising against the traditional constraints or the other "self" in the aspiration of individuality coupled with the romanticism of the nineteenth century and the promotion of specialized professions. These individualistic products aimed at structuring the center of metropolises represent the topical or specialized gathering of these individuals and will be dynamic and rational so long as the collective interests (i.e. individuals in the community) and the group interests (i.e. common groups) are discussed. Here, Simmel holds another belief: "Instead of trying to produce a systemic and conceptual thought about modernity, he tried to create a space for experiencing the modern life that can lead to a modern framework for the life in new societies. He sought social experience in a social life, based on which the modern society could be depicted not as a single entity but 
as a reciprocal set of interactivity and interactive forms. In his opinion, "the forms are the aspects of the sciences studying human action that enable the production of society and sociology" (Farizabi, 2005, 16). The molds are in the form of architecture or the revealed visions of citizens! In today's form, the frames require more convergence because the invitation of a citizen and audience to the place or geography of the formplace means that he should be moved from point A to point B. Now, consider the Simmelian notion: "Life in metropolises is possible only with the rationality and application of rational powers such as computation, time and order; otherwise, life in such cities is not possible" (Metropolis and mental life -1992). Now, if we imagine this architectural request in the citizen's participation in observing it from the standpoint of individuality in the Simmelian metropolis, then we would be caught in a trap which is the result of an abstract distance. He (Simmel) emphasizes the creation of the individual and individuality in the city, because a person can be freed from the prehistoric or traditional collective belongings in the city to find his personal identity. A person is brought under the pressure of various forces in the city, in which he creates an unbelievable feeling which leads him to a corner and causes him to distance himself from others. Thus, in modern metropolis, individualism has become a major source for the process of social differentiation and can create many urban identities" (Fukuhi-2004 - 177).

As two places of collision, the neighborhood and architecture can reduce or rationalize these real and abstract distances, part of which are seen today in the absence of movement from any point to other points or places. If we consider the new forms of internet-based jobs and the absence of employees at workplace as well as the virtual bureaucracy and the elimination of referrals of clients to offices, there is a new locus for the production of a widespread range of exciting entertainments and, more importantly, virtual spaces where the citizens of any age can symbolize, show or even institutionalize any form or a major part of their emotional-sexual drives. As anticipated by Simmel who had depicted this reality a hundred years ago within a theory about the era of individual liberties with the monetary system, the numerous urban identities found in social determinants and monetary value-based exchanges are either multiplied or reduced in a fluctuation. The superstructures derived from the monetary systems directly discuss how citizens (actors) are influential in such a way that every citizen (actor) views himself trapped in the virtual reality of the actual products of the metropolis at the unique moment of his choice. However, he also believed that "the collapse of individual culture through the complete victory of objective culture will be the cause of the strong and bizarre hatred that the preachers of extreme individualism and mostly Nietzsche have gained from the metropolis" (Craibe, 2005, 286).

Now, let us raise this question again: what can the neighborhood and architecture do as a place for the conjunction of citizenship activists in this highly volatile era of virtual infrastructures?

The future in which the neighborhood or architecture can be objectified is the freedom that the metropolis (city) and its belongings (neighborhood and architecture) have demanded, because the neighborhood is a reflective mirror of the representation of all the past and future potentials of a city throughout all ages! 


\section{The Simmelian metropolis and the individuality of freedom}

"Metropolis is a conceptual location emerging and functioning due to the gap between the objective and cultural cultures of the mind caused by the monetary economy and the division of labor. The metropolitan experience of people is coupled with the new business and displacement in social opportunities and the speed of contact with others. Changes made in the perception and understanding of modern metropolitan areas are partly due to the fact that the viewer-audience and the images of objects, street and exhibition sites are movable. Everything is in motion or everything is founded on movement (Metropolis and the Metropolis Life - 1992). The tragedy as noted by Simmel is where the objective culture has taken over all aspects of life and has overcome the creative spirit of the modern individual. In Aristotle's view, the tragedy is where the imitation of virtue culminated in the fate of the certainty. In this sense, the tragedy in the present era is where human questions are left unresolved, so that perhaps a new fate with a new function will allow the accumulation of constantly changing foundations. Nevertheless, architecture is where the tragedy of individualism is multiplied in the metropolis scenes in the unoriginal forms of theater (types of choreographies, theaters, apartments, happenings, the axial objects, the environment, the creation of cyborgs, online theater, etc.) where these individual or citizenship differences are brought together! [What is the most important component of this gathering: the metropolitan citizen's autonomy, the applied and interactive architecture or the different forms of urban dynamism!?]. Consider this delicate point of view suggested by Simmel: “... at the same time, in the metropolis, there is an explanation that reduces the effects and influences of modern and everyday life on the self-consciousness of individuals; on this basis, the individual resists the heavy forces of the objective culture" (Wendenberg, 2007, 45-60). When does one get tired of the images of objects, street landscapes and exhibitions to resist subsequently? "The urban Man of the Simmelian metropolis nurtures an organ that protects him against the threatening events and contradictions of the external environment (outside the individuality of citizenship and the virtual and secure environment of the metropolis) that could eradicate him. He reacts with his own brain, not with his heart, thus the metropolises are deeply embedded in the monetary economy (because they are developing and reintroducing the doctrines that make the brain a means of observing and calculating). The complexity of the life of cities forces us to value punctuality, accountability, and accuracy and turn the world into a mathematical problem. A city-dweller (or perhaps the citizen) is a person who avoids getting involved with emotions on the one hand and protects himself from the negligence of the other side by adopting a cautious attitude towards others. Therefore, although individuals are physically close together, they are psychologically isolated and independent of others which makes it possible for a person to have a great deal of freedom" (SherbethianSimmel as a sociologist of modernism).

The theory: if the city and architecture can influence and persuade the minds in their reflection of objectivity to come closer, the consequence would be the physical beings (or individualities) with an abstract distance and the real distance influenced by the space derived from the architectural physics and the spirit of the city. They will meet each other again and then they will have a tangible understanding (a simple sense and 
touchable reality) of the real metropolitan life.

Your city will call you for the reconstruction and consolidation of the shape in which you can live. You will also rebuild yourselves. Resolve upon who you are and the city around you will take the fixed form. In this respect, one has to resolve upon the essence of a city. Your identity will be before your eyes as a triangulated map. Cities are unlike the villages and settlements, which are naturally moldable. We can shape them in our imagination and they shape us, in turn, by their resistance against our attempt to impose our own form on them. In other words, life in the city seems to be a kind of art, and we need artistic and light vocabularies to impede the particular human and material relationship that exists in the continuous creative play of urban life. As you imagine, the city holds the illusions, myths, dreams and real nightmares and can be more realistic than the hard city observed on the maps, statistics, and the monographs of urban sociology, demography and architecture.

In his book titled "Cities over the Edinburgh Tower", Patrick Gades pointed out that urban organism should be considered as a human mass constantly affected by its near and far-reaching points in the course of its transformation. Gades wanted all scientific findings to be used to achieve this goal. From his point of view, the city is a complex system composed of different structures and categories as an interdisciplinary subject. Therefore, the traditional methodology of urban planning should be pursued according to the practical model based on a professional and physical activity on the empirical perceptions and urban self-perception.

What will the research variables (neighborhood and architecture) needed for this metropolitan gathering of individuals? Blending with the latest technologies! Becoming the essence which is both the subject and object while being functionalist! The pure pursuit of amusement (the originality of amusement)! Become a technological realm! Duplicating the special and topical places! Or something that includes all these responses!?

In order to get closer to a functional and applied proposition, a definition of humanconstructed location oughtto be presented in the general field.

\section{The public space or the human-constructed location [neighborhoods, architecture, infrastructure]}

The public space in the city needs to be defined in the form of architecture. In the definition of architecture, the general views and the exercise of power and the poetic form are avoided. On the other hand, in presenting or introducing the tools on which it is based, the mechanism of the efficiency of these tools and the definitive structure are addressed so that it can guarantee the input provided independently of the time and the particular place. Without trying to offer a definition for this "definition", we only refer to the point that the tastes and the spirit of building science and the technology of the use of materials for building materials are discussed regardless of these terms in the paper that we have before us. This important and abstract change helps the independence of the definition from time to place.

Accordingly, the public spaces in the city must be defined and designed in accordance with the city's culture and actions. In this sense, the suitable urban fabric can be created 
commensurate with the culture of modernism and architecture-technology. The physical architecture is thus created in the city with regard to the social behaviors and the cultural and artistic uses with artistic or cultural motivations about the day-to-day events in the area of technology, human and civil relations as they are inherently unstable in time. However, they apparently seem to be functional and are considered as crucial components in the creation of architectural ambience. This set of relationships is also based on the ideas of human beings and their tastes, needs and values.

"The place of humans manifests, completes, and symbolizes their understanding of the environment and can also bring together or interconnect a number of meanings (Norberg Schultz, 79, 2012). "The indicator of the quality of every human-constructed place is an enclosure with spatial features." "In metaphysical thought, there is always something absent from the human relationship with the world, so there is always a kind of vacuum, intolerance, or empty space between man and the world and this empty space is called the place or ottos" (Agamben, 2012, 51).

Heidegger: "The spaces take their existence from the places and not the space" (ibid. 24). "Man-made places have a function of gathering and concentrating". This means the human being receives the environment and focuses it on buildings and objects (ibid. 27). By these definitions, a public space is something other than the environment or the structure of environments. A public space exists when it can overcome the balance between a collective identity (social or cultural) and a land. A metropolis is regarded as a laboratory for socialization when it makes something very special from the urban structure which is filled with emptiness like a sponge that absorbs and repels the airflow and constantly changes the extent of its cavity. The public space does not allow the use of any space and if anything can be changed in it, it would be a partial change and ownership. The public space has changed today and has become a venue. The only adjective that is most appropriate for the public location is 'availability'. It describes the availability of applications and the effects of discrimination. Thus, the public place accepts the intrusive or aggressive force even though it has not yet established its position and has not yet given up its freedom of movement (Isaac Joseph, 1984, 41).

A public space that includes any individuality with any interest is the most prone place to display and share a few things. A case in point is the latest local achievements (in any area) of the metropolis. The second item is bringing together all the tastes and subsequently giving equal rights to all the present citizens (actors) which means that they allow a pause to be formed between citizens by themselves as a result of their differences. The third quality is dividing the public spaces into specialized spaces by the notion that there are common properties and special categories in the generality of a location. The fourth quality is that the public space which is essentially a representation of the overall atmosphere of the metropolis is also the best place for the idea of urban development in modern metropolises as they need to present themselves by different forms of entertainment, fun and more importantly, in aesthetic forms by the artistcitizens to the other citizens and guests. The fifth element is that the public space that has given a nature and direction to the earth-ground in the form of combined architectural shapes can draw upon the steps and the use of various forms of steps to invoke a metaphorical view of the individual-economic distinctions of the citizens with regard to the contrast in its levels for the intervals of the minds. 
This combination of individual identities in our public domain requires us to provide a definition for location-identity.

\section{Location-identity (genius loci), money and the determination of the status of will}

Location: "What is meant by the location is clearly more than an abstraction. It is the general purpose of things which is made up of the objective materials, shapes, textures and colors. These things create an environmental quality which is the basis of the place. In general, a place has a character or atmosphere. Accordingly, a place is a qualitative phenomenon that we cannot reduce to smaller attributes like its spatial relations without losing its objective nature. The places that are complex and the qualitative totalities of a single nature cannot be described in terms of analytical and scientific concepts. In essence, science makes the realities more abstract in order to achieve objective and unbiased knowledge" (Norberg Schultz, 2012, 17). Martin Heidegger: "The place is the deep and complex aspect of human experience of the world." Gabrielle Marcel: "A person is not apart from his place; he is the same as the place." The relationship between man and place is based on a mutual and reciprocal interaction, and the same action in the future creates its memory and identity. The environment or the place creates the identity from two perspectives, one of which is the perceptual-cognitive aspect traced back to the subject of memories and the other item is the body which involves the sense of belonging to a special place. In this way, the spaces trigger different feelings among different individuals and the role of personality and past experiences of individuals is also effective in getting this feeling. The identity of the location is a part of a personal identity that grows through the direct experience of the physical environment. Thus, the identity is a reflection of the social and cultural aspects of the place-environment. For example, the link that one has to one's place of birth, growth and life is the main source of individual and collective identity. Simmel holds that the aspects of formal places are deeply related to transient and variable (and even opposing) aspects in metropolitan relationships which are the aspects of closeness and farness, separation and connection, the border and openness, the fixedness and mobility, the attached and abstract location, the abstraction and places, the unity and detachment and the inside and outside. He also believes that the community is captured within a social geometry and cannot manifest itself as a whole. "Every human being lives at the confluence of several forms and not in all of them; thus, even the closest people to a person may conceal the most fundamental dimensions of their existence in modern society." (Metropolis and spiritual life - 2005 - 279). According to Simmel, modern life penetrates everything. Ironically, Simmel defines the dialectics of distance and proximity of the social distance as privacy and a certain distance in the monetary economy that seems to be related to the separation of people and objects as a monetary and metropolitan discourse. He also considers causality as a social, voluntary, and unpredicted category" (Frieszbi, 2005-279). As stated by Simmel, in the economic society, money has become a social instrument and has more power than any other kind of mental energy called reasoning which is free from emotions and feelings. In his view, the economic structure is part of the larger objective entity of society, which alienates the 
mental nature of humankind. In his view, the objective nature of society that embraces the economy is inherent in human life and is unchangeable (Dileini - $2010-186)$. The wealth expands the direction of rationality towards the world (similar to Marx and Marx Weber), but this rationality might be distorted for some people who seek the money in an irrational way as a goal in itself. For example, a miserly citizen is a character or social category that knows happiness only in relation to money without having to own and use certain things. By separating emotional conflicts from economic transactions, the wealth makes it possible for business partners to grow in number. Freedom leads the individual to break the bonds of the first group (for example, family or tribe) and promotes individualism in this way. The money encourages one to adopt future-orientation as looking at the world in terms of novelty and speed and thus destroys the respect and attachment to relationships (Simmel, 1907: 344 quoted by Kiwisto, 1999: 175).

\section{Sustainability and modern urban development [Sustainable Architecture, Modernism, Neighborhoods]}

As a modern approach to urban development, new urbanism takes into account the whole gamut of urban planning, design and architecture which are created in response to unstable neighborhoods. The Importance of the survey or analysis of this model is due to its impact on the planning at all levels and the consideration of socioeconomic and environmental issues. Michael Redcliffe considers the term 'sustainable development' as an indication of ecological doctrines in the economic process. Moreover, the principles provided by this theory are of great importance in urban development, new developments, and the intrinsic development of texture especially in the planning of urban neighborhoods. Accordingly, the principles proposed in this approach have a close relationship with the criteria of sustainability. According to Jaykumer, sustainable society is a society in which environmental constraints are regarded. Such a society is not a society without growth but a society in which growth constraints are identified thereby addressing alternative growth paths. In this context, the growth of urbanization and the emergence of large cities and metropolises are one of the most important issues that have been considered globally in the last few decades. The increasing population of cities and the resulting problems have created a new form of city, urbanization and urbanism. Therefore, the urban geography must also be of new dimensions and territories to provide an appropriate urban environment for citizens (or actors).

One of the first steps to modernize the city is the Athenian Charter, which was the result of the work of the fourth Siamese conference in 1933 in Brussels with the theme of urbanization in the hands of the great architect Le Corbusier. In this charter, for the first time, an interpretation of the mechanism and the functioning of the city was provided with the generalizability of what was discussed to any human habitat that could be considered as a city in the separation of places and the four uses (i.e. residence, work, leisure time, communications). Le Corbusier envisions the future cities that are made up of massive and tall skyscrapers while each of these multi-functional skyscrapers accommodate about 100,000 people who live and work there. In these buildings, the residential apartments, offices, stores, schools, caucuses and all the needs of a large 
neighborhood are provided. The inhabitants of these complexes are far from the smoke and traffic noise of cars and instead enjoy sunlight and beautiful views.

Sustainable development is one of the issues that is now given much importance and is determined by the United Nations as the twenty-first century agenda. Sustainable development is a kind of development that will meet today's needs without reducing the ability of the future generations to meet theirs. Obviously, we must ensure the welfare of the future generations through the conservation of natural resources and ecological systems. If the concept of sustainability is to improve the living standards, we must also exploit a part of today's natural resources. The concept of sustainable urban development is also the result of the environmentalist debate about the environmental issues, especially the urban environment, which was provided after the proposal of sustainable development theory to support environmental resources.

In fact, sustainable development is an appropriate development that pursues the goals of sustainable development in three main aspects and approaches to the future: 1. Environmental sustainability, 2- economic sustainability, 3- social sustainability. Thus, the realization of sustainable development requires the realization of all these aspects together.

Another important indicator for achieving sustainable development is the achievement of social sustainability, as the focus of sustainable development is human and human society and development without considering humankind is meaningless. In this regard, it is necessary to identify the environmental limitations of human activities in relation to cities and the implementation of design methods with these constraints. This theory focuses on the prevention of urban, regional and national pollution, reducing the capacity of local, regional and national production, support for recycling, the rejection of harmful developments and the elimination of the gap between the poor and the wealthy. In addition, the means to achieve these goals are urban, rural, regional, and national plans according to the law controlling the uses in urban or rural areas (Ziari, 2001). The level of urban sustainability shows the quality of life in cities. Understanding the situation of neighborhoods and the bottlenecks in their development in terms of sustainability and sustainable development is one of the issues recently addressed by the urban planning culture.

Accordingly, four characteristics of sustainable development can be identified: productivity (system dynamics), justice (the fair distribution of opportunities), flexibility (the restoration or maintenance of the level of productivity in irregularities) and stability (the capacity of the community for the future use). The result is a development pattern that must have the ability to adapt to a range of social and economic changes and cultural values of the society over a period of time. In this regard, modern urbanization is somehow the direction of the postmodern generation and the urban planners and developers. At the same time, new urbanism pays particular attention to the planning and design at the neighborhood level (public space) and the adjacent unit that shares some values with the criteria of sustainability in public places. The perspective of sustainable development refers to the dissatisfaction with the results of economic development and economic growth in cities from the ecological point of view. Hence, sustainable development means meeting the needs of the present generation without harming the ability of the next generation to meet its needs. In order to achieve a desirable sustainable 
growth policy, Terner believes that sustainable development should be such that it will prevent the destruction of natural-national capital and reserves, while adopting a real per capita income growth rate.

Although the category of sustainability is very idealistic, its comprehensiveness is broad enough to be considered at different levels of the city. Considering the issue of sustainable urban development in modern urban planning and the widespread attention that it receives, the consideration of planning and design based on sustainability at the level of neighborhoods and the architecture derived from this fact is an important topic in recent years because the achievement of goals is more tangible at micro levels.

\section{Conclusion}

Today's world is a technological and cybernetic world. The world is surrounded by a variety of media, which are rapidly changing and evolving. Modern urban development is one of the challenges of the twenty-first century. The rapid growth and expansion of urbanization have consequences for urbanism in a new age. As a real need for citizens, urban activities are among the most important requirements even in the virtual world. Information technology is the best tool for the development of justice among people without any exception. Especially in this century, the life experienced in the virtual space is an integral part of citizenship. The use of virtual space is presently an undeniable necessity of nature. The effective application of information technology in the field of urban design and architecture and planning involves the identification of opportunities and constraints, the formulation of proper planning, taking into account social and economic factors along with the provision of technological, communicative, televised, legal, and executive infrastructures. Therefore, development in the true sense of the word must have many characteristics including an acceptable goal, inclusiveness, conformity to ethical norms and desires to be labeled as the development of the city. If we want any progress in urban sustainability, it is necessary to establish a communication between the city's form and some of its elements on all geographical scales. A very common definition of sustainable development is provided by WCED, according to which the development is the ability to respond to the current needs without reducing the ability of the next generations to meet their needs.

What is certain is the main factor behind the success of a sustainable urban development which is known as technology. Every day, new versions of mobile technologies and communications are sent to the markets with a variety of capacities. It is imperative to maintain the advantages of competition and making profit and reap the benefits of using modern technologies under a specific work model.

What is concluded from this research is that the city is related to architecture and architecture depends on humans while they depend on their environment (natural environment - technology). Given the prominence of the virtual world and the application of the simulated space as a non-objective reality, the architecture derived from human thinking has opened its place in this high-risk atmosphere and uses technology as a means of emergence in the world of objective reality. Then, the city takes its body from the humans and architecture which is a human-constructed mentality. The city is not an exception to this rule and cities must also view technology as a tool and use 
it in the direction of modern urban development in a way that does not impinge on the overall structure of the metropolitan context. The metropolitan position is to ensure the well-being of citizens and the safety (sustainability) of the environment within urban structures in today's world.

\section{References}

[1] Simmel, George, Metropolis and the Spiritual Life, Translation by Yousef Abazari, Social Science Letter, Phase 6, No. 3, Volume 2, Publication of the Faculty of Social Sciences of Tehran University, 1993.

[2] Biancini, Franco, The Subjective View of the City (Concepts, Cultural Representations, and Policies), Translated by Mohammad Ali Zakariae, Tisa Publication, 2014.

[3] Harvey, David, The Postmodernity Situation (Research in the Origins of Cultural Change) Translator: Aref Aghvami Moghadam, Second Edition, Pazhwak Publication, 2014.

[4] Freysea, David, Georg Zimmel, Translated by Javad Ganji, First Edition, Gam Now Publishing, 2006.

[5] Kiwisto, Peter, Fundamental Thoughts in Sociology, Translated by Manouchehr Saboori, First Edition, Ney Publisher, 2008.

[6] Fakouhi, Nasser, Urban Anthropology, First Edition, Ney Publication, 2004

[7] Fialkov, Yatelek, Urban Sociology, translated by Abdolhossein Nikshahr, first edition, Agah Publication, 2004.

[8] Gideon, Siegfried, Space, Time and Architecture, Translated by Manouchehr Mazini, Scientific and Cultural Publishers, 2007.

[9] Falamaki, Mohammad Mansour, The Origins and the Theoretical Approaches of Architecture, Third Edition, Faza Publishing, 2010.

[10] Dileini, Tim, The Classical Sociology Theories, Translated by Behrang Sedighi and Vahid Toloui, Third Edition, Ney Publsihers, 2010.

[11] Rieters, George, Theories of Sociology in the Contemporary Era, Translated by Mohsen Salasi, Tenth Edition, Scientific Publishing, 2005.

[12] Agamben, Giorgio, Childhood and History (about the destruction of experience), Translated by Pooya Amini, Center publication, 2012.

[13] Norberg Schultz, Christine, The Soul of Place (towards the Phenomenology of Architecture), Translated by Mohammad Reza Shirazi, Rokhad-e Nou Publication, 2009.

[14] Nohi, Hamid, Thoughts on Art and Architecture (Essay Collection), Ganj Honar Publication, 2009.

[15] Smith, Gregory Bruce, Nietzsche, Heidegger, and Transition to Postmodernity, Translated by Alireza Seyed Ahmadian, Porsesh Publishing, First Edition, 2001.

[16] Sharifian, Ehsan, Intermediate Growth Development, Using the City's Inland Capacities, Manzar Journal, (10): 50-47, 2010.

[17] Lange, Kevin, The Theory of City Form, Translation by Seyyed Hossein Bahreini, Tehran University Press, 2005.

[18] Hajipour, Khalil, Ketabchi, Emad, Hosseinpour, Mohammad, New Urbanism, A Way to Sustainable Neighborhoods, 2012.

[19] Collins, Peter, History of Architecture Theory: The Transformation of Ideals in Modern Architecture, Translated by Hossein Hasanpour, Second Edition, Ghatre Publishing, Tehran, 2008.

[20] Alberti, Leon Battista, On the Art of Building in Ten Books,Translated by Joseph Rykwert, Neil Leach \& Robert Tavernor, The MITPress, Cambridge, Massachusetts and London, 1988.

[21] Simmel, G. The Philosophy of the Money, Third edition published by Routledge, New York. 2004.

[22] www.scottbankert.net/UrbanArtsParis/Readings/Class 1/Simmel... P PDF file.

[23] Easterling, P.E, The Cambridge Companion to Greek Tragedy, Cambridge University Press, 1997. 